\title{
Cell proliferation alterations in Chlorella cells under stress conditions
}

\author{
Carmen Rioboo ${ }^{a}$, José Enrique O’Connorb, Raquel Pradoa, Concepción \\ Herreroa ${ }^{a}$ Ángeles Cida1
}

Aquatic Toxicology, Volume 94, Issue 3, 14 September 2009, Pages 229-237

Received 29 April 2009, Revised 7 July 2009, Accepted 12 July 2009, Available online 16 July

2009

DOI: 10.1016/j.aquatox.2009.07.009

\section{Abstract}

Very little is known about growth and proliferation in relation to the cell cycle regulation of algae. The lack of knowledge is even greater when referring to the potential toxic effects of pollutants on microalgal cell division. To assess the effect of terbutryn, a triazine herbicide, on the proliferation of the freshwater microalga Chlorella vulgaris three flow cytometric approaches were used: (1) in vivo cell division using 5-,6-carboxyfluorescein diacetate succinimidyl ester (CFSE) staining was measured, (2) the growth kinetics were determined by cytometric cell counting and (3) cell viability was evaluated with the membrane-impermeable double-stranded nucleic acid stain propidium iodide (PI).

The results obtained in the growth kinetics study using CFSE to identify the microalgal cell progeny were consistent with those determined by cytometric cell counting. In all $C$. vulgaris cultures, each mother cell had undergone only one round of division through the $96 \mathrm{~h}$ of assay and the cell division occurred during the dark period. Cell division of the cultures exposed to the herbicide was asynchronous. Terbutryn altered the normal number of daughter cells (4 autospores) obtained from each mother cell. The number was only two in the cultures treated with $250 \mathrm{nM}$. The duration of the lag phase after the exposure to terbutryn could be dependent on the existence of a critical cell size to activate cytoplasmic division. Cell size, complexity and fluorescence of chlorophyll $a$ of the microalgal cells presented a marked light/dark (day/night) cycle, except in the non-dividing $500 \mathrm{nM}$ cultures, where terbutryn arrested cell division at the beginning of the cycle. Viability results showed that terbutryn has an algastatic effect in $C$. vulgaris cells at this concentration.

The rapid and precise determination of cell proliferation by CFSE staining has allowed us to develop a model for assessing both the cell cycle of $C$. vulgaris and the in vivo effects of pollutants on growth and reproduction at microalgal cell level.

\footnotetext{
${ }^{1}$ a Laboratorio de Microbiología, Facultad de Ciencias, Universidad de A Coruña, Campus da Zapateira s/n, 15008 A Coruña, Spain b Laboratorio de Citómica, Unidad Mixta de Investigación CIPF-UVEG, Centro de Investigación Príncipe Felipe, Avda. Autopista del Saler, 16, 46013 Valencia, Spain
} 


\section{Abbreviations}

- a.u., arbitrary units;

- CFSE, 5-,6-carboxyfluorescein diacetate succinimidyl ester;

- DC, daughter cell;

- FCM,flow cytometry;

- FL, fluorescence;

- FS, forward light scatter;

- MC, mother cell;

- PI, propidium iodide;

- SS,side light scatter

\section{Keywords}

CFSE; Chlorella; Cell division; Flow cytometry; Herbicide; Proliferation; Viability

\section{Introduction}

During the last few decades, the use of herbicides in agriculture has become the principal method for controlling weeds (Eullaffroy and Vernet, 2003). Despite all the efforts to develop safer pesticides, more environmentally benign, more target specific, less persistent in the surrounding areas, the application of which can be carried out less frequently and in small quantities, these substances continue to present a serious threat to terrestrial and aquatic ecosystems (Forbes and Forbes, 1994). The herbicide studied in this work, terbutryn ( $N$-tertbutyl- $N^{4}$-ethyl-6-methyl-tio-1,3,5-triazine-2,4-diamine), belongs to the group of triazines, which affect photosynthesis at photosystem II level ( Tomlin, 2003). According to its persistence in the aquatic ecosystems and its potential for causing environmental damage, terbutryn is included in the European Union priority list of pesticides established for Mediterranean countries with the aim of monitoring them by water authorities (Bengtson Nash et al., 2005). In fact, in Spain terbutryn is one of the most frequently detected triazines in surface and groundwaters, usually at concentrations higher than 600 nM (Hernández et al., 1998 and Carabias-Martínez et al., 2003).

Among all organisms in aquatic ecosystems, microalgae are key targets in pollution cases, especially those caused by herbicides, for two basic reasons: their ecophysiological similarities with terrestrial plants (the potential sensitivity of the same metabolic processes) (Leboulanger et al., 2001) and their role as primary producers (any change in the proliferation of the primary producers could provoke a global alteration in the equilibrium of the aquatic ecosystems) (Campanella et al., 2001 and Rioboo et al., 2007). These characteristics support the use of the freshwater microalgae in laboratory toxicological assays. Nowadays, the development of microalgal toxicity assays is increasing, as reflected by the fact that these assays are mandatory for the notification of chemical compounds in the European Union (Leboulanger et al., 2001). 
The species selected in the present work was Chlorella vulgaris Beijerinck, a freshwater microalga used in toxicity assays ( Nalewajko and Olaveson, 1998).

Cell division is one of the most important and fundamental processes in all living organisms. In unicellular organisms, as microalgae are, life cycle is the same as the cell cycle (Yamamoto et al., 2003). However, since most studies in algae have focussed on the photosynthetic processes, there are scarce data about their growth and proliferation in relation to the cell cycle regulation (Oldenhof et al., 2004),

a phenomenon which is even more pronounced in the case of microalgae. The complexity of distinguishing the different cell proliferation phases of a microalgal species by means of microscopy hinders the analysis of its cell cycle. So far, cell proliferation based on DNA replication or on radioactive labelling, generally with tritiated thymidine, has not been successfully applied to calculate the number of generations of microalgal cells. In relation to this point, flow cytometry (FCM) allows the rapid determination of a high number of cell functions by using a great variety of biochemically specific, non-toxic and fluorescent molecules in conditions close to the in vivo status in short-term exposures to high levels of light ( Carter and Meyer, 1990). Indeed, previous studies have reported the successful implementation of this technique in toxicity studies with microalgae (Franqueira et al., 2000, Franklin et al., 2004 and Adler et al., 2007). The intracytoplasmic vital dye 5-,6-carboxyfluorescein diacetate succinimidyl ester (CFSE) has been widely used as a cell marker in quantitative studies of cell division in the lymphocyte proliferation ( Kamau et al., 2001). Nevertheless, no data exist about its application in vegetal cells. In addition, this cytometric technique allows the individual analysis of microalgal mother cells and the identification of their daughter cells rather than the analysis at a population level ( Lyons et al., 2001).

Furthermore, the development and application of methods for the detection of contaminants based on the physiological response of organisms have become a high priority objective with the purpose of providing an early warning of sublethal pollution (Eullaffroy and Vernet, 2003). Growth is the most widely studied parameter in chronic toxicity testing using microalgae (Van Wezel and Van Vlaardingen, 2004). Taking into account all these points, the aim of the present work was to study $C$. vulgaris cell proliferation and to assess the effect of the terbutryn on the proliferation capacity of this freshwater microalga by FCM. Three flow cytometric approaches were used to monitor the herbicide effect: (1) CFSE staining to measure the in vivocell division, (2) cytometric cell counting to determine the growth kinetics and (3) staining with the membrane-impermeable nuclear stain propidium iodide $(\mathrm{PI})$ to evaluate the cell viability. Moreover, the cell size, complexity and autofluorescence of the $C$. vulgaris cells were analysed.

\section{Materials and methods}

\subsection{Microalgal cultures}


C. vulgaris Beijerinck (Chlorellaceae) obtained from the Culture Collection of Algae and Protozoa of the Institute of Freshwater Ecology (Cumbria, UK) (strain CCAP 211/11B) was grown on sterile Bristol medium (Brown et al., 1967).All cultures were carried out in triplicates in sterilized Pyrex glass bottles containing $40 \mathrm{ml}$ of medium. For the assays, the inoculum was taken from a 3-day-old culture, with the aim of using cells growing in a logarithmic phase in all experiments. After being incubated with the fluorochrome CFSE, the stained cells were properly resuspended in Bristol medium by adjusting the initial cell density of the experimental cultures to $9 \times 10^{6}$ cells $\mathrm{ml}^{-1}$. Microalgal cultures were maintained at $18 \pm 1{ }^{\circ} \mathrm{C}$, illuminated with $70 \mu$ mol photons $\mathrm{m}^{-2} \mathrm{~s}^{-1}$ and continuously aerated under a light/dark cycle of $12 / 12 \mathrm{~h}$.

\subsection{Terbutryn treatment}

At time 0 , the terbutryn was added to the CFSE-stained cultures at different final concentrations: 12.5, 25, 50, 100, 250 and 500 nM. Terbutryn was the Riedel de Haën Pestanal standard for environmental analysis (>99.5\% purity; RdH Laborchemikalien GmbH \& Co., Seelze, Germany). Herbicide stock solutions (1 mM) were prepared by dissolving the herbicide in $100 \%$ methanol and filtering through $0.2 \mu \mathrm{m}$ membrane filters. Final methanol concentration never exceeded $0.05 \%(\mathrm{v} / \mathrm{v})$ and no measurable effects of solvent were observed in any of the assayed parameters (data not shown). CFSE-stained cultures without herbicide or methanol were included as controls in all experiments.

\subsection{Flow cytometric analysis of microalgal cells}

Flow cytometric analyses of $C$. vulgaris cells were performed in a Coulter Epics XL4 flow cytometer (Beckman Coulter Inc., Fullerton, CA, USA) equipped with an argon-ion excitation laser $(488 \mathrm{~nm}$ ), detectors of forward (FS) and side (SS) light scatter and four fluorescence detectors corresponding to four different wavelength intervals: 505-550, 550-600, 600-645, and $>645 \mathrm{~nm}$. Starting from time 0 of the tests, samples were taken from each culture every $12 \mathrm{~h}$ for the different cytometric analyses. This coincides with the beginning of the period of light and the beginning of the period of darkness. Samples were taken up to $96 \mathrm{~h}$ of the assay. For each analysed parameter, data were recorded in a logarithmic scale and results were expressed as mean values obtained from histograms in arbitrary units (a.u.). Fluorescence of chlorophyll $a(>645 \mathrm{~nm})$ was used as a FCM gate to exclude non-microalgal particles. At least 100,000 cells per culture were analysed. Data were collected using listmode files and statistically analysed using the EXPO 32 ADC software (Beckman Coulter Inc.).

\subsubsection{Cell division}

The technique based on the serial dilution of the fluorescence intensity of the stable intracellular-binding fluorochrome CFSE (Sigma Chemical Co., St. Louis, MO, USA) was optimized to study the cell division in the proliferation of $C$. vulgaris by means of a FCM analysis. The vital dye CFSE consists of a fluorescein molecule containing two acetate moieties 
and a succinimidyl ester functional group. In this form, it is membrane permeant and nonfluorescent. When incubated with cells, the fluorescein-based CFSE crosses the cell membrane into the intracellular environment, where endogenous esterases remove the acetate groups, whereby the molecule acquires identical spectral characteristics to fluorescein. Fluorescein is a highly fluorescent molecule with an optimal excitation of $488 \mathrm{~nm}$ (with argon laser light), and strong emission at $519 \mathrm{~nm}$. Due to its high polarity, fluorescein is non-permeant to the cell membrane, being trapped within intact cells. In addition, the succinimidyl ester reacts with free amine groups of cytoplasmic proteins, forming dye-protein adducts. Proteins with a low turnover rate, including some cytoskeletal components, are thought to be responsible for the very longlived staining by CFSE. Upon subsequent cell division, the cytoplasmic CFSE fluorescence of each mother cell is equally redistributed among the daughter cells at mitosis, allowing the division history of population to be determined at a cell level ( Lyons et al., 2001). A CFSE stock solution was prepared by dissolving the fluorochrome in dimethyl sulfoxide (DMSO; Sigma Chemical Co., St. Louis, MO, USA) and stored at $-20^{\circ} \mathrm{C}$. Microalgal cells were incubated with CFSE at a final concentration of $8 \mu \mathrm{g} \mathrm{ml}^{-1}$ per $150 \times 10^{\circ}$ of $C$. vulgaris cells resuspended in Bristol medium for $30 \mathrm{~min}$ at $18{ }^{\circ} \mathrm{C}$ and in darkness before being cultured. CFSE-stained cells (checked by epifluorescence microscopy) were resuspended in Bristol medium $\left(9 \times 10^{6}\right.$ cell $\left.\mathrm{ml}^{-1}\right)$ and distributed in cultures to which the different terbutryn concentrations assayed were added afterwards. All cultures were maintained for $96 \mathrm{~h}$ in a chamber under the conditions described above. As above, cultures without CFSE and non-stained cultures with DMSO were carried out. With this staining protocol, no significant differences were observed among growth curves of CFSE-stained cultures, cultures without CFSE and non-CFSE-stained cultures with DMSO. Moreover, the fluorescence intensity of CFSE-stained cells remained unvariable during the assay period. The fluorescence of fluorescein was analysed in the FL1 detector (505-550 nm) of the flow cytometer.

\subsubsection{Growth measurement}

The growth of $C$. vulgaris cultures was measured by FCM counting of total microalgal cells present in a known volume of culture. Photosynthetic single-cell microorganisms generally show very strong natural fluorescence due to the presence of chlorophyll and/or other pigments like carotenoids or phycobiliproteins (Cunningham, 1993). In C. vulgaris cells, autofluorescence corresponds to the signal gathered in the FL4 detector $(660-700 \mathrm{~nm})$, emitted by the chlorophyll $a$ and related pigments after being excited at $488 \mathrm{~nm}$. This autofluorescence was used to exclusively analyse intact microalgal cells and to exclude non-microalgal particles, selecting those which showed red fluorescence, which indicates the presence of chlorophyll (Trask et al., 1982 and Olson et al., 1983). Based on this fact, fluorescence of chlorophyll $a$ (FL4; $660-700 \mathrm{~nm}$ ) was used as gate to allow the analysis of $C$. vulgaris growth. Daily growth rate (DGR) (day-1) was calculated for periods of $24 \mathrm{~h}$ using the following formula: 
$\mathrm{DGR}=\frac{\left[\ln \left(N_{t}\right)-\ln \left(N_{0}\right)\right]}{\ln 2\left(t-t_{0}\right)}$

where $N t$ is the cell density (cells $\mathrm{ml}^{-1}$ ) at time $t$ (days) and $N_{0}$ is

the cell density at time to.

\subsubsection{Cell viability}

Fluorescence of cells stained with propidium iodide (PI; Sigma Chemical Co., St. Louis, MO, USA) was analysed by flow cytometry to assess cell viability. PI is a vital dye that intercalates with double-stranded nucleic acids to produce red fluorescence when excited with blue light. Due to its polarity, this fluorochrome is unable to pass through intact cell membranes. However, when a cell dies, integrity of the cell membrane fails and $\mathrm{PI}$ is able to enter and stain nucleic acids (Ormerod, 1990). Fluorescence was recorded in a logarithmic scale between 605 and $635 \mathrm{~nm}$ (FL3 detector) in a flow cytometer. Hence, PI can be used to discriminate between live non-fluorescent cells and non-viable fluorescent cells. Thermal death by microwave heating was included as control of the probe. Aliquots of $1 \times 10^{6} \mathrm{cells} \mathrm{ml}^{-1}$ were resuspended in phosphate buffered saline solution (PBS; pH 7.4) and stained with PI to a final concentration of $3 \mu \mathrm{g} \mathrm{ml}^{-1}$ for $15 \mathrm{~min}$ at room temperature and in darkness. This fluorochrome concentration allows the staining of all non-viable cells, without affecting autofluorescence or being toxic to the viable cells. The viability of $C$. vulgariscells was expressed as the percentage of viable cells $v s$. the total amount of cells analysed by flow cytometry.

\subsubsection{Cell size, complexity and autofluorescence}

Since the forward light scatter (FS) is correlated with the size or volume of a cell or particle and the side light scatter (SS) is correlated with the intracellular complexity (Shapiro, 1995), aliquots of $10^{6}$ cells $\mathrm{ml}^{-1}$ were resuspended in PBS and analysed by flow cytometer to study the potential alterations in the cell size or intracellular complexity of $C$. vulgaris cultures. In the same way, the autofluorescence of $C$. vulgaris cells (FL4 detector; $660-700 \mathrm{~nm}$ ) was analysed by FCM to study the potential changes in the chlorophyll a content of microalgae. Only viable cells were analysed.

\subsection{Data analysis}

All experiments were carried out in triplicates with three replicates per assayed terbutryn concentration and data were statistically analysed by a one-way analysis of variance (ANOVA) using the SPSS 14.0 software. When significant differences were observed, means were compared by the multiple range Duncan test. Significant differences at a level of significance of $0.05(P \leq 0.05)$ are represented by an asterisk $\left(^{*}\right)$. Data are given as mean values \pm standard errors of the means.

\section{Results}




\subsection{Cell division}

The FCM analysis of the CFSE-stained cells showed that the concentration of terbutryn in culture medium affected cell division of $C$. vulgaris ( Fig. 1 and Fig. 2).
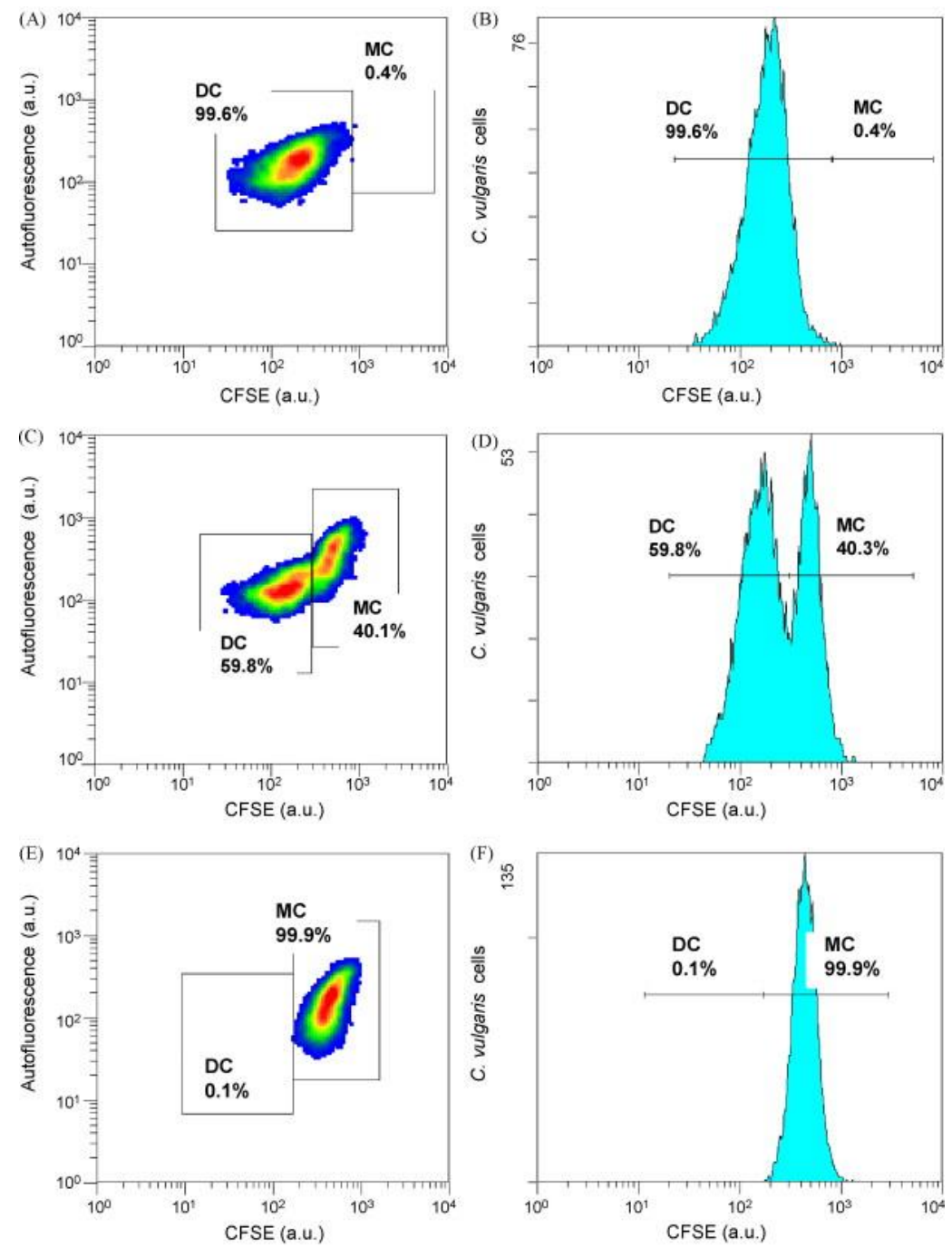

Fig. 1.

Flow cytometric analysis of the cell proliferation of $C$. vulgaris cultures after $96 \mathrm{~h}$ of exposure to $0 \mathrm{nM}$ (A and $B), 100 \mathrm{nM}(C$ and $D)$ and $500 \mathrm{nM}(E$ and $F)$ concentrations of terbutryn. (A, C and $E$ ) Biparametric histogram of $C$. vulgaris CFSE-stained cells (a.u.) vs. autofluorescence (a.u.). (B, D and F) Monoparametric histogram of $C$. vulgaris CFSE-stained cells (a.u.). MC, Mother cells; DC, daughter cells; a.u., arbitrary units. 


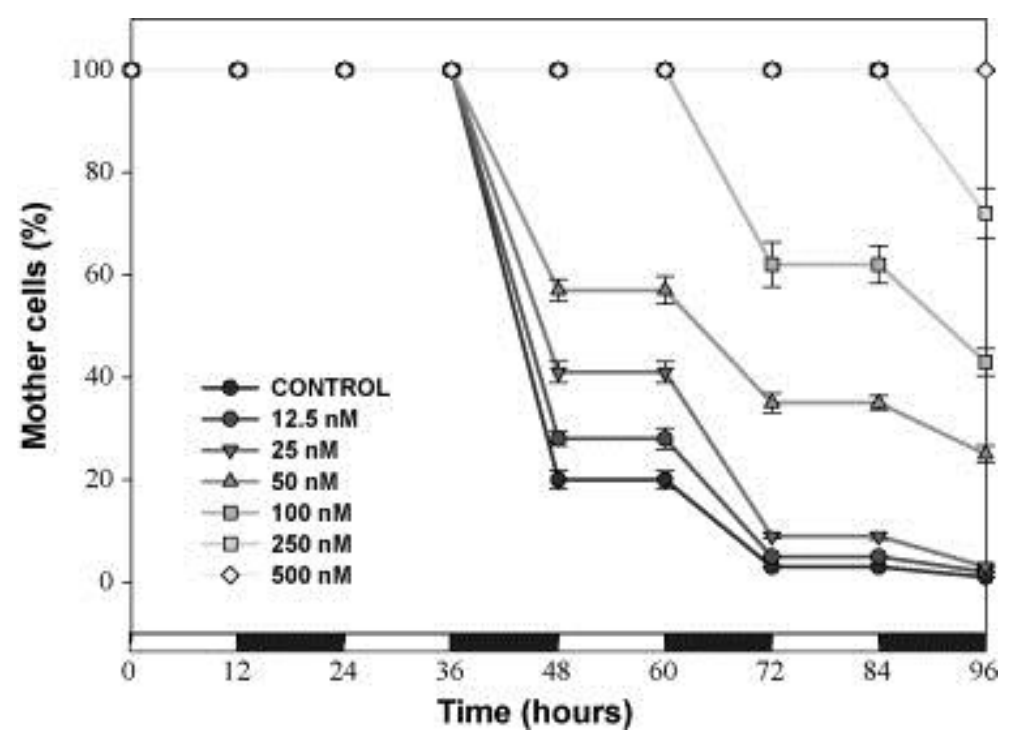

Fig. 2.

Cell proliferation of $C$. vulgaris cultures exposed to different concentrations of terbutryn as a function of time, expressed as the percentage of mother cells existing in each culture with respect to microalgal population. Black and white bars indicate dark and light periods, respectively.

One of the advantages of this technique is the ability to analyse viable cells which have undergone defined numbers of cell divisions by FCM, i.e., to determine how many generations have occurred (Lyons et al., 2001). In the present work, when the microalgal cells divided, as a result of the distribution of fluorochrome among the cytoplasms of the daughter cells in both control cultures and in cultures exposed to the herbicide, two peaks of fluorescence were observed: the more intense fluorescence corresponded to the mother or undivided cells (MC) and the less intense fluorescence corresponded to the daughter or divided cells (DC) (Fig. 1). The analysis of the cytograms throughout the $96 \mathrm{~h}$ of treatment showed that the cytoplasmic division of the $C$. vulgaris cells took place during the periods of darkness, both in the control cultures and in the herbicide-treated ones ( Fig. 2).

The exposure to terbutryn provoked a negative effect on the microalgal division which was more pronounced when the concentration of the herbicide in the culture medium increased (Fig. 2).

After $96 \mathrm{~h}$ of assay, $99.95 \%$ of the microalgal population of the control cultures was formed by daughter cells as compared to $57.56 \%$ and $28.28 \%$ of divided cells observed in the 100 and $250 \mathrm{nM}$ cultures, respectively. In the cultures treated with the highest terbutryn assayed concentration $(500 \mathrm{nM})$, cells of the microalgal population did not divide. Mother cells formed $100 \%$ of the cells present in these cultures after $96 \mathrm{~h}$ of treatment (Fig. 1 and Fig. 2).

The cell division of $C$. vulgaris cultures was asynchronous, both in the control cultures and in the herbicide-treated ones ( Fig. 2). With an increase of the terbutryn concentration in the medium, an increase in the asynchronization in the division of the microalgal cells was observed. In the control cultures, $80.72 \%$ of the mother cells divided in only one period of darkness, whereas in the cultures treated with $50 \mathrm{nM}$ of the herbicide, $75.58 \%$ of the population divided after 3 periods of darkness ( Fig. 2). 


\subsection{Growth}

The growth of $C$. vulgaris cultures was affected by terbutryn, as reflected by the daily growth rates, which were calculated as the number of times that the microalgal population duplicated in periods of $24 \mathrm{~h}$ ( Table 1). The toxic effects provoked by terbutryn on $C$. vulgaris growth were detected after $48 \mathrm{~h}$ of exposure to the herbicide, when all the herbicide-treated cultures showed statistically lower daily growth rates than those observed in control cultures $(P<0.05)$. $C$. vulgaris cultures exposed to herbicide concentrations equal to or above $100 \mathrm{nM}$ began to grow later than control cultures. This delay increased as the concentration of herbicide in the medium became greater. In the cultures exposed to the highest terbutryn concentration assayed, $500 \mathrm{nM}$, no grow was observed during the $96 \mathrm{~h}$ of assay.

Table 1.

Daily growth rate (DGR) of $C$. vulgaris cultures with different concentrations of terbutryn calculated for $24 \mathrm{~h}$ periods.

Terbutryn (nM) DGR $\left(\right.$ day $\left.^{-1}\right)$

\begin{tabular}{|c|c|c|c|c|}
\hline & $0-24 \mathrm{~h}$ & $24-48 \mathrm{~h}$ & $48-72 \mathrm{~h}$ & $72-96 \mathrm{~h}$ \\
\hline CONTROL & $0.00 \pm 0.00$ & $1.92 \pm 0.11$ & $0.32 \pm 0.02$ & $0.04 \pm 0.00$ \\
\hline 12.5 & $0.00 \pm 0.00$ & $1.69 \pm 0.06^{*}$ & $0.58 \pm 0.04 *$ & $0.05 \pm 0.00$ \\
\hline 25 & $0.00 \pm 0.00$ & $1.51 \pm 0.07 *$ & $0.72 \pm 0.03^{*}$ & $0.08 \pm 0.00 *$ \\
\hline 50 & $0.00 \pm 0.00$ & $1.17 \pm 0.04 *$ & $0.58 \pm 0.02 *$ & $0.28 \pm 0.01 *$ \\
\hline 100 & $0.00 \pm 0.00$ & $0.00 \pm 0.00^{*}$ & $0.85 \pm 0.03^{*}$ & $0.56 \pm 0.01 *$ \\
\hline 250 & $0.00 \pm 0.00$ & $0.00 \pm 0.00^{*}$ & $0.00 \pm 0.00^{*}$ & $0.60 \pm 0.02 *$ \\
\hline 500 & $0.00 \pm 0.00$ & $0.00 \pm 0.00^{*}$ & $0.00 \pm 0.00^{*}$ & $0.00 \pm 0.00^{*}$ \\
\hline
\end{tabular}

Asterisks indicate statistically significant differences with respect to the values of control cultures $(P<0.05)$.

\subsection{Cell viability}

Cell viability in $C$. vulgaris cultures assayed by FCM was not significantly affected $(P>0.05)$ by the addition of terbutryn to the medium ( Table 2), remaining close to $100 \%$ for all herbicide concentrations assayed.

Table 2.

Cell viability of $C$. vulgaris cultures after $24,48,72$ and $96 \mathrm{~h}$ of exposure to different concentrations of terbutryn expressed as the percentage of viable cells with respect to the total amount of cells analysed by flow cytometry.

Terbutryn (nM) Viability (\%)

\begin{tabular}{l|llll}
\cline { 2 - 5 } & $24 \mathrm{~h}$ & $48 \mathrm{~h}$ & $72 \mathrm{~h}$ & $96 \mathrm{~h}$ \\
\hline CONTROL & $99.99 \pm 0.01$ & $99.99 \pm 0.01$ & $99.84 \pm 0.03$ & $99.79 \pm 0.05$ \\
\hline 12.5 & $99.98 \pm 0.02$ & $99.98 \pm 0.02$ & $99.90 \pm 0.04$ & $99.78 \pm 0.06$ \\
\hline 25 & $99.97 \pm 0.03$ & $99.95 \pm 0.03$ & $99.81 \pm 0.05$ & $99.71 \pm 0.03$ \\
\hline 50 & $99.98 \pm 0.02$ & $99.88 \pm 0.04$ & $99.81 \pm 0.04$ & $99.68 \pm 0.07$ \\
100 & $99.94 \pm 0.01$ & $99.86 \pm 0.04$ & $99.76 \pm 0.06$ & $99.70 \pm 0.04$ \\
250 & $99.92 \pm 0.02$ & $99.86 \pm 0.05$ & $99.85 \pm 0.06$ & $99.64 \pm 0.05$
\end{tabular}


Terbutryn (nM) Viability (\%)

\begin{tabular}{|c|c|c|c|c|}
\hline & $24 \mathrm{~h}$ & $48 \mathrm{~h}$ & $72 \mathrm{~h}$ & $96 \mathrm{~h}$ \\
\hline 500 & $99.94 \pm 0.03$ & $99.86 \pm 0.02$ & $99.82 \pm 0.05$ & $99.68 \pm 0.06$ \\
\hline
\end{tabular}

3.4. Cell size, complexity, and autofluorescence

The size, complexity and autofluorescence of $C$. vulgaris cells showed a marked light/dark cycle, except for those cultures treated with $500 \mathrm{nM}$ of terbutryn ( Fig. 3A-C). 

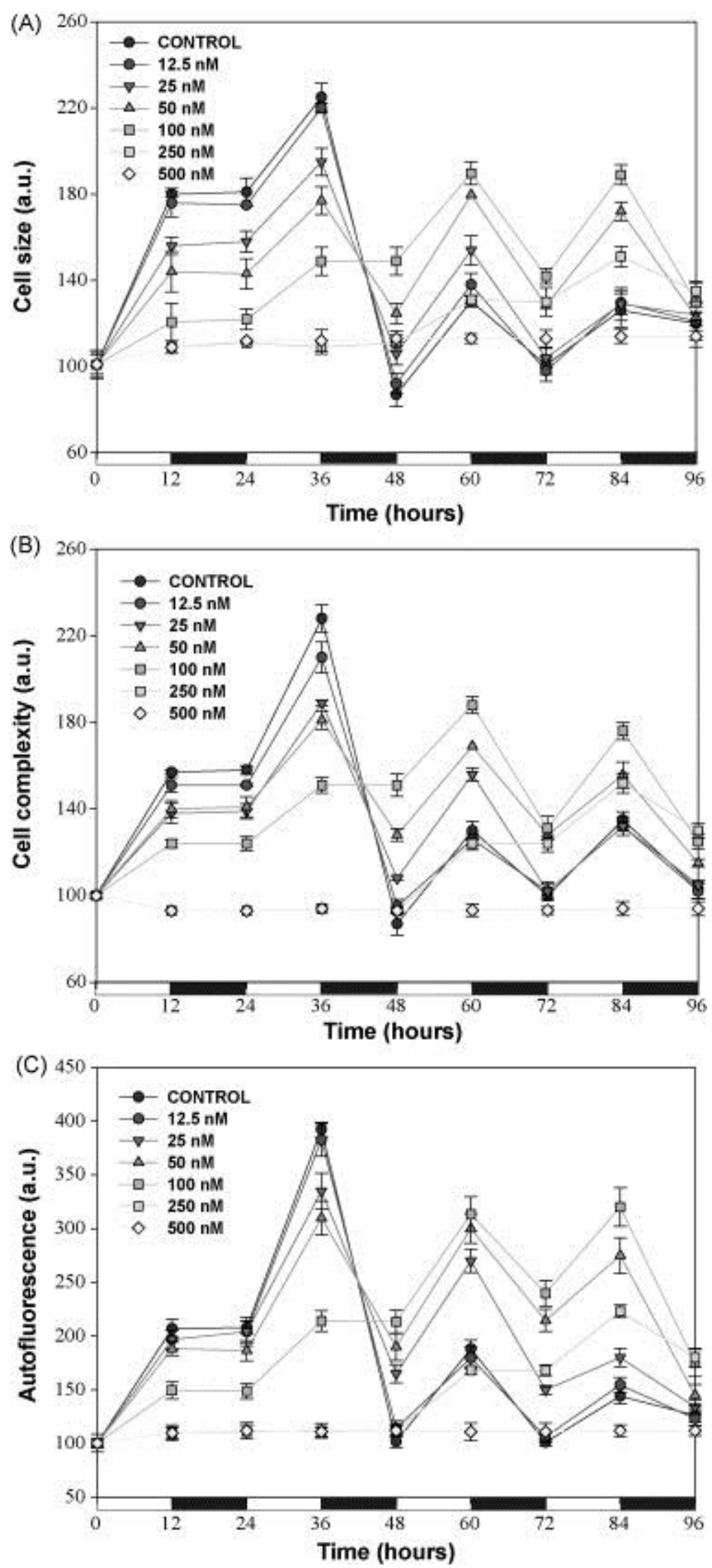

Fig. 3.

Cell size (A), complexity (B) and autofluorescence (C), analysed by FCM, of $C$. vulgaris cultures exposed to different concentrations of terbutryn as a function of time. Black and white bars indicate dark and light periods, respectively. 
Throughout the periods of light, an increase in the values of the three parameters in the microalgal cells was recorded in both control cultures and those exposed to the herbicide, except for the cultures treated with the highest concentration of herbicide, whose values did not vary significantly during the $96 \mathrm{~h}$ of assay (Fig. 3A-C).

Concerning size and cell complexity, both parameters showed an increase of the same magnitude, the initial basal values were doubled (Fig. 3A-C). Cell autofluorescence also increased during the periods of light, but to a greater degree than the previous parameters: the basal values were quadruplicated. Size, cell complexity and autofluorescence of microalgal cells remained invariable during the periods of darkness until when cultures began to grow. These time points were at $36 \mathrm{~h}$ of experiment in control cultures and in cultures with the lowest assayed concentrations of terbutryn, and at 60 and $100 \mathrm{~h}$ in cultures treated with 100 and 250 $\mathrm{nM}$ terbutryn, respectively. From these dark periods, the values of the three parameters diminished until reaching the basal levels (Fig. 3A-C).

\subsection{Cytokinesis}

During the cytokinesis, the ratios between mean values of size, complexity, autofluorescence and the peak of CFSE-fluorescence of mother cells and daughter cells were analysed by flow cytometry to determine the number of daughter cells produced in each division round (Table 3), with the exception of the cultures exposed to $500 \mathrm{nM}$ of terbutryn where daughter cells were not observed. The analysis of mother and daughter cell subpopulations showed that mean values of size and cell complexity of mother cells were double of those of daughter cells in both control cultures and those treated with terbutryn, except for the cultures exposed to $250 \mathrm{nM}$ of herbicide (Table 3). In those cultures, the size of the mother cells was 1.48 times greater than that observed in daughter cells, while the cell complexity between the types of cells gave a relation of 1.62. In the control cultures and in cultures exposed to terbutryn, the fluorescence of the chlorophyll a of mother cells of $C$. vulgaris was quadruple of the value obtained for daughter cells ( Table 3), except for the cultures treated with $250 \mathrm{nM}$ of herbicide. In these cultures, mother cells showed twice as much autofluorescence as daughter cells.

Table 3.

Relationship between mean values of size, complexity, autofluorescence and fluorescein-based CFSE emitted fluorescence of mother and daughter cells in $C$. vulgaris cultures exposed to different concentrations of terbutryn.

\begin{tabular}{|l|l|l|l|l|}
\hline Terbutryn $(\mathrm{nM})$ & Cell size & Cell complexity & Autofluorescence & CFSE \\
\hline CONTROL & $2.12 \pm 0.16(48)$ & $2.03 \pm 0.08(48)$ & $4.05 \pm 0.17(48)$ & $4.14 \pm 0.13(48)$ \\
\hline 12.5 & $2.13 \pm 0.05(48)$ & $2.00 \pm 0.09(48)$ & $4.08 \pm 0.17(48)$ & $4.06 \pm 0.17(48)$ \\
\hline 25 & $2.16 \pm 0.09(48)$ & $1.97 \pm 0.07(48)$ & $3.96 \pm 0.15(48)$ & $3.99 \pm 0.21(48)$ \\
\hline 50 & $1.94 \pm 0.10(48)$ & $1.97 \pm 0.11(48)$ & $4.09 \pm 0.19(48)$ & $4.09 \pm 0.15(48)$ \\
\hline 100 & $2.02 \pm 0.06(72)$ & $2.08 \pm 0.12(72)$ & $4.06 \pm 0.14(72)$ & $3.92 \pm 0.16(72)$ \\
\hline 250 & $1.48 \pm 0.07(96)^{*}$ & $1.62 \pm 0.02(96)^{*}$ & $2.19 \pm 0.11(96)^{*}$ & $2.03 \pm 0.19(96)^{*}$ \\
\hline 500 & - & - & - & - \\
\hline
\end{tabular}

The time point of the analysis, expressed in hours of exposure, is indicated in brackets. Asterisks indicate statistically significant differences with respect to the values of control cultures $(P<0.05)$. 
In control cultures and in cultures exposed to herbicide, the intensity of the peak of CFSEfluorescence of mother cells was four times greater than that observed in daughter cells, except for the cultures treated with $250 \mathrm{nM}$ of herbicide, where the CFSE-fluorescence of the daughter cells was half of that in mother cells (Table 3). Obviously, daughter cells were not observed in the $500 \mathrm{nM}$ terbutryn cultures.

\section{Discussion}

The analysis by means of flow cytometry of the CFSE-stained cells showed that the concentration of terbutryn in the culture medium affected cell proliferation of $C$. vulgaris, being in concordance with that observed when referring to daily growth rates ( Table 1; Fig. 2). C. vulgaris cultures with herbicide concentrations of at least $100 \mathrm{nM}$ showed a prolonged lag phase compared to the control cultures. This lag phase became longer as the concentration of herbicide in the culture increased. Indeed, the $500 \mathrm{nM}$ cultures remained in this phase after $96 \mathrm{~h}$ of exposure ( Table 1; Fig. 2). This fact suggests that the assayed herbicide could have a sublethal effect on the $C$. vulgaris cells since microalgae were capable of dividing after a period of adaptation. For this reason, cell viability studies were carried out ( Table 2). The viability results showed that $99.68 \%$ of the cells exposed to $500 \mathrm{nM}$ of terbutryn were viable after $96 \mathrm{~h}$ exposure, confirming that terbutryn has an algastatic and sublethal effect on $C$. vulgaris cells. Several studies have also reported this capacity of adaptation of microalgae to the toxicity of another triazine (atrazine), not only in terms of growth but also of returning to the basal levels of different parameters observed before the exposure to the herbicide such as photosynthesis and biomass( Langan and Hoagland, 1996 and Muñoz et al., 2001).

The observation of only one peak of daughter cells in all microalgal cultures indicated that each mother cell underwent only one division cycle after $96 \mathrm{~h}$ from the beginning of the assay, meaning that only one generation was produced (Fig. 1).

Currently, there are no studies that report the existence of sexual reproduction in C. vulgaris. Chlorella is a haploid organism ( Kadono et al., 2004) that reproduces asexually by autosporulation. The strain used in our studies presented three phases in its life cycle: (1) growth of mother cells, (2) cell division and (3) liberation of daughter cells ( Fig. 4). One of the critical points in the regulation of the cell cycle is coordinating the cell volume growth and the division process in order to maintain cell size ( Oldenhof et al., 2004)

. In control and herbicide-treated C. vulgaris cells, a temporal separation between the cell volume growth and the formation of autospores (cell division) was produced. This is reflected by the fact that the size, complexity and autofluorescence of $C$. vulgaris presented a marked light/dark cycle, except in the cultures treated with $500 \mathrm{nM}$ of terbutryn ( Fig. 3A-C). The growth of mother cells was produced during the light periods ( Fig. 3A) while cytoplasmic division and liberation of the daughter cells of $C$. vulgaris took place during the periods of darkness, as is generally described for microalgae ( Tamiya, 1966 and Edmunds, 1988), both in the control cultures and in the herbicide-treated ones ( Fig. 2). The microalgal population at time 0 of the 
assay was characterized by being homogeneous, with a small size and a little complexity and chlorophyll fluorescence per cell. In the control cultures, a first phase of cell growth characterized by an increase in size, cell complexity and autofluorescence was observed during the lag phase ( Fig. 3A-C). C. vulgaris cells grew during two light periods until duplicating their size. After reaching this moment, microalgal cells began to divide during the following period of darkness. At the same time that the increase in size is produced, the chlorophyll autofluorescence underwent an important increase, which could indicate that the photosynthetic apparatus is being multiplied. This active metabolism is also reflected by the increase of cell complexity registered by FCM.

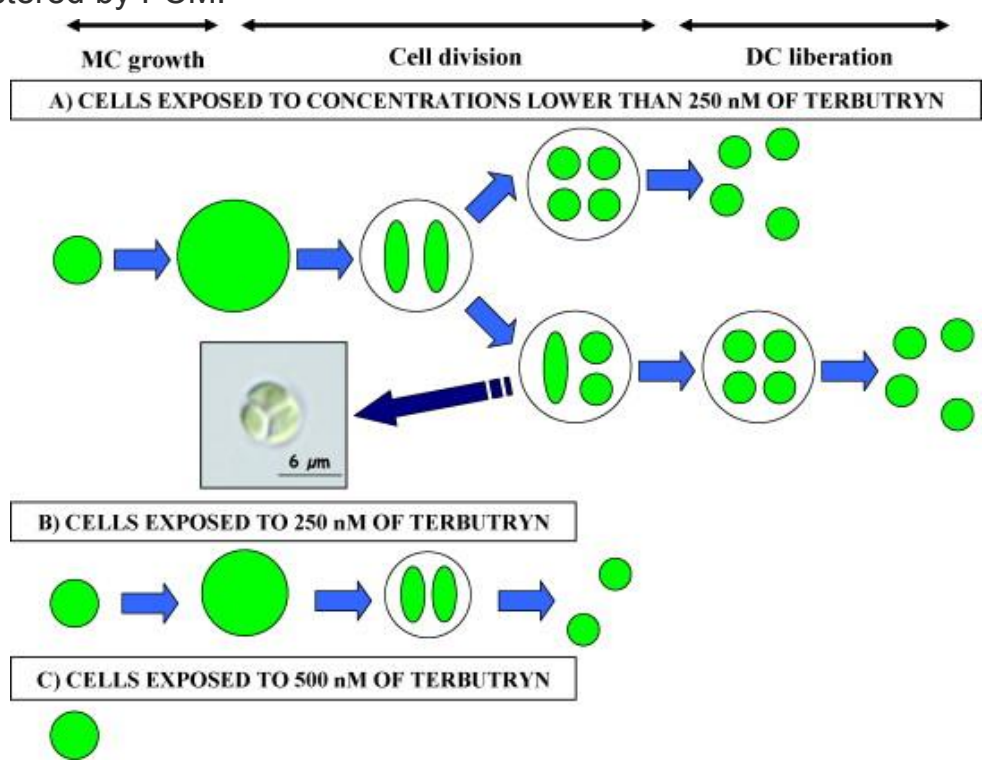

Fig. 4.

Effect of terbutryn on the capacity for cell proliferation in $C$. vulgaris. The cell cycle of the Chlorellastrain used in this study could be divided in three phases: growth of mother cells, cell division and daughter cell liberation. (A) In both control cultures and cultures exposed to terbutryn concentrations lower than $250 \mathrm{nM}$, the liberation of four daughter cells was observed after the first mitosis followed by a cytoplasmic division and two additional simultaneous mitoses. However, the higher the concentration, the higher the proportion of mother cells showing three protoplasts inside as a result of a temporary separation of two consecutive autosporulation processes. This was observed even in control cultures although in minor proportion. (B) In cultures exposed to $250 \mathrm{nM}$ terbutryn, the liberation of two daughter cells took place from a mother cell smaller than the one observed in control cultures. (C) In cultures exposed to the highest assayed concentration, terbutryn arrested the progression of the $C$. vulgaris cell cycle at the first phase level. See text for further details.

During the dark period, the size remained invariable. When the mother cells divided, the daughter cells were of smaller size, which was concurrently associated with a decrease of the FS signal of the cells during the periods of darkness. Due to the cell divisions, a parallel decrease in both cell size and complexity was observed. The relative contents of chlorophyll per cell also decreased but to a greater extent than the previous parameters.

Referring to size, microalgal cells increased in size until becoming large enough for completing the cell cycle and dividing during the period of darkness (Fig. 3A). In fact, the microalgal cells exposed to terbutryn needed a longer cell growth period than the control cells in order to reach 
large enough cell size to start to divide. This indicated the existence of a critical threshold size for $C$. vulgaris cells to complete their growth phase and begin their division phase, being a key control point triggering microalgal cell cycle. Indeed, in this moment, $C$. vulgaris cultures started the logarithmic growth phase when cells began to divide ( Table 1; Fig. 2). In other words, the lag phase of microalgal cultures corresponded with the growth period of the cells and was marked by the time the cells required to attain that critical size. Terbutryn delayed the onset of that process and the beginning of the division in the period of darkness, probably because this herbicide blocks the photosynthetic electron transfer. In the present study, the cell division is produced when the mother cells are double the size of the daughter cells ( Table 3). Similar results of cell size have been described for Chlamydomonas reinhardtii ( Matsumura et al., 2003). Regarding to the role of a critical cell size control, Altenburger et al. (2008) have highlighted the need of establishing criteria for the cell size distribution of the initial population in ecotoxicity assays using microalgae. In accordance with the general observation that populations that have reached this cell volume threshold will divide irrespective of any stress, the selection of a constant cell size distribution is critical to avoid potential interferences of a heterogenous microalgal size population in the interpretation of the effects of pollutants.

Size and complexity of $C$. vulgaris cells were duplicated before cytokinesis ( Table 3 ), suggesting that two daughter cells emerged from each mother cell ( Kwok, 2003). However, during the cell cycle of the control cells and the cells treated with the lowest concentrations assayed, the data of the CFSE staining reflected that four autospores were liberated ( Table 3), as it is usually described for this species following a $2 n$ series (Lupi et al., 1998). For that reason, conclusions based only on those cytometric parameters can lead to erroneous results.

On the other hand, the fluorescence of the chlorophyll a is a parameter sensitive enough for the study of the cell cycle of this microalga. Approximately $90 \%$ of the chlorophyll fluorescence is originated in the photosystem II, target of terbutryn action. For this reason, in the presence of this herbicide, an immediate reaction in the emission of fluorescence by the microalgal cells is expected ( Bengtson Nash et al., 2005). However, this variation has not been recorded so far by means of a flow cytometer like that used in this study. The bimodal character of the histograms reflected the redistribution of the chlorophyll between the mother cells and the resultant cells of the cell division ( Gerashchenko et al., 2001 and Gerashchenko et al., 2002).

CFSE-based staining together with the fluorescence of chlorophyll permitted the characterization of discreet subpopulations of the different phases of the cell cycle of $C$. vulgaris ( Fig. 1A, C and E).

In both control cultures and cultures exposed to terbutryn concentrations lower than $250 \mathrm{nM}$, microalgal cells underwent a first mitosis followed by a cytoplasmic division and then other two simultaneous mitosis, which resulted in the liberation of four daughter cells. A stage consisting of three protoplasts inside the mother cells wall was observed in these cultures, even in control ones though in a minor proportion (Fig. 4A). The appearance of mother cells with three autospores could be the result of the temporal separation of the two processes of autosporulation (consecutive divisions). In the case of the mother cells in the $250 \mathrm{nM}$ cultures, 
the liberation of the daughter cells took place after the first mitosis (Fig. 4B). Therefore, when dividing, the mother cells of the control cultures and those of the lowest concentrations produced four daughter cells per mother cell, while the cells exposed to a terbutryn concentration of $250 \mathrm{nM}$ produced two, as reflected the ratio between fluorescein-based CFSE emitted fluorescences of mother and daughter cells in these $C$. vulgaris cultures ( Table 3). This heterogeneity of the proliferating activity of microalgae could be related to the decrease recorded in the cell volume growth of the mother cells when exposed to $250 \mathrm{nM}$ of herbicide with respect to control values. These results support the hypothesis that terbutryn alters the cell cycle of an apparently homogenous microalgal population at level of the cell growth of the mother cells.

In favorable conditions such as the control cultures are, $C$. vulgaris cells did not divide at the same time. Numerous studies have indicated that in culture cell cycle of microalgal cells is related to the light/dark cycles ( Parpais et al., 1996). Other authors have synchronized cultures of unicellular algae of the Chlamydomonas or Scenedesmus genera by manipulating the light/dark cycles ( Lemaire et al., 1999). The cells of the C. vulgaris control cultures, under the described culture conditions, divided asynchronously and entered division at different times. The asynchronism observed in our control cultures suggests that experimental conditions (batch culture, light intensity, etc.) were not optimal to obtain a total synchronization of the cultures of this strain of $C$. vulgaris.

In the case of the cultures exposed to terbutryn, the higher the concentration, the fewer the cells dividing in each period of darkness (Fig. 2). Some cells did not divide at all during the treatment while others did, but at different times. Taking into account that cell size distribution of the initial population was apparently homogenous, one interpretation of this asynchronous division is the existence of different activation thresholds into microalgal division as a consequence of terbutryn exposure (Lyons, 2000). Three control points, called restriction points, basically exist in the cell cycle of any eukaryotic organism. A first one is located in the G0/G1 transition, a second in the G1/S transition and a third in the G2/M transition. When facing any genotoxic damage, the eukaryotes can detain the cell cycle at any of these points in order to permit the repairing of the DNA damage (Smith and Fornace, 1996). The progression from G0 to G1 means the beginning of the proliferation process. During G1 phase, cells grow. They increase in size and weight, and synthesize RNA and proteins, which is a prerequisite for the mitosis (Kwok, 2003). In the cultures exposed to the highest assayed concentration, the progression of the $C$. vulgaris cell cycle was stopped at the first phase of the cycle ( Fig. 4C). It is well known that microalgal growth, most often the $\mathrm{G} 1$ progression, requires photosynthetic light energy for a metabolic demand. As the results of size, autofluorescence and complexity ( Fig. 3A-C) reflected, terbutryn blocked the increase in cell size as well as the synthesis of cell components, which finally suggests that this photosynthesis-inhibiting herbicide arrests the G1 progression of the cell cycle of $C$. vulgaris. Once again, all these data confirm the existence of a mechanism strictly linked to a critical cell size that controls the $\mathrm{G} 1$ progression of $C$. vulgaris cell cycle, as 
other authors have recently proposed for Scenedesmus quadricauda (Vitova and Zachleder, 2005).

\section{Conclusions}

Our study demonstrates that the analysis of the microalgal cell proliferation by staining with CFSE presents several advantages: it is easy, fast, and does not require the manipulation (e.g. making permeable) of the cells for their staining. Moreover, it is not necessary to resort to radioactive genetic marking such as ${ }^{51} \mathrm{Cr}$ or tritiated thymidine, which complicates the handling of the samples or need specific installations. All that is required is a flow cytometer with only one laser. CFSE is a universal marker, used initially for lymphocytes (there is no available bibliography that describes the use for microalgae) and its staining is stable and non-toxic for the cell, which permits long-term assay like the present one. In addition, the study of the degree of synchronization at the nuclear DNA level in microalgal cells is complicated because of the difficulty of isolating intact nuclei due to the presence of the cell wall. This in vivo CFSE staining permits the estimation of the degree of synchronization of Chlorella cultures without analysing nuclear DNA content. Finally, the analysis by means of FCM of the cell proliferation of $C$. vulgaris exposed to the terbutryn herbicide has proved to be a very sensitive parameter, in terms of both the concentration of the herbicide and the reaction time of the cell. Indeed, this CFSE-based protocol allows differentiating between effects on cell volume increase and cell division which would be helpful to diagnose different modes of action of pollutants. This characteristic endorses its application with microalgae as a biomarker in bioassays of both chronic and acute toxicity.

\section{Acknowledgements}

This work was carried out with the financial support of the Spanish Ministerio de Educación y Ciencia (CGL2004/02037BOS). R.P. acknowledges a F.P.U. fellowship form the Spanish Ministerio de Educación y Ciencia.

\section{References}

N.E. Adler, M. Schmitt-Jansen, R. Altenburger

Flow cytometry as a tool to study phytotoxic modes-of-action

Environ. Toxicol. Chem., 26 (2007), pp. 297-306

R. Altenburger, M. Schmitt-Jansen, J. Riedl

Bioassays with unicellular algae: deviations from exponential growth and its implications for toxicity tests results

J. Environ. Qual., 37 (2008), pp. 16-21 
S.M. Bengtson Nash, P.A. Quayle, U. Schreiber, J.F. Müller

The selection of a model microalgal species as biomaterial for a novel aquatic phytotoxicity assay

Aquat. Toxicol., 72 (2005), pp. 315-326

T.E. Brown, F.L. Richardson, M.L. Vaughn

Development of red pigmentation in Chlorococcum wimmeri (Chlorophyta: Chlorococcales)

Phycologia, 6 (1967), pp. 167-184

L. Campanella, F. Cubadda, M.P. Sammartino, A. Saoncella

An algal biosensor for the monitoring of water toxicity in estuarine environments

Water Res., 35 (2001), pp. 69-76

R. Carabias-Martínez, E. Rodríguez-Gonzalo, M.E. Fernández-Laespada, L. Calvo-Seronero, F.J. Sánchez-San Román

Evolution over time of the agricultural pollution of waters in an area of Salamanca and Zamora (Spain)

Water Res., 37 (2003), pp. 928-938

N.P. Carter, E.W. Meyer

Introduction to the principles of flow cytometry

M.G. Ormerod (Ed.), Flow Cytometry A Practical Approach, Oxford University Press, Oxford, UK (1990), pp. 1-28

A. Cunningham

Analysis of microalgae and cyanobacteria by flow cytometry

D. Lloyd (Ed.), Flow Cytometry in Microbiology, Springer-Verlag, London, UK (1993), pp. 131-142

L.M. Edmunds Jr.

Cellular and Molecular Bases of Biological Clocks

Springer-Verlag, New York (1988) 497 pp.

P. Eullaffroy, G. Vernet 
The F684/F735 chlorophyll fluorescence ratio: a potential tool for rapid detection and determination of herbicide phytotoxicity in algae

Water Res., 37 (2003), pp. 1983-1990

N.M. Franklin, J.L. Stauber, R.P. Lim

Development of multispecies algal bioassays using flow cytometry

Environ. Toxicol. Chem., 23 (2004), pp. 1452-1462

D. Franqueira, M. Orosa, E. Torres, C. Herrero, A. Cid

Potential use of flow cytometry in toxicity studies with microalgae

Sci. Total Environ., 247 (2000), pp. 119-126

V.E. Forbes, T.L. Forbes

Ecotoxicology in theory and practice

M.H. Depledge, B. Sanders (Eds.), Ecotoxicology Series 2, Chapman \& Hall, London, UK (1994), p. 247

B.I. Gerashchenko, T. Kosaka, H. Hosoya

Growth kinetics of algal populations exsymbiotic from Paramecium bursaria by flow cytometry measurements

Cytometry, 44 (2001), pp. 257-263

B.I. Gerashchenko, T. Kosaka, H. Hosoya

Optical compartmentation of vegetating algae species as a basis for their growth-specific characterization

Cytometry, 48 (2002), pp. 153-158

F. Hernández, C. Hidalgo, J.V. Sancho, F.J. López

Coupled-column liquid chromatography applied to the trace-level determination of triazine herbicides and some of their metabolites in water samples

Anal. Chem., 70 (1998), pp. 3322-3328

T. Kadono, T. Kawano, H. Hosoya, T. Kosaka

Flow cytometric studies of the host-regulated cell cycle in algae symbiotic with green paramecium 
Protoplasma, 223 (2004), pp. 133-141

S.W. Kamau, R. Nuñez, F. Grimm

Flow cytometry analysis of the effect of allopurinol and the dinitroaniline compound (Chloralin) on the viability and proliferation of Leishmania infantum promastigotes

BMC Pharmacol., 1 (2001), pp. 1471-1481

\section{A.C. Kwok}

Cellulose synthesis is coupled to cell cycle progression at $\mathrm{G} 1$ in the dinoflagellate Crypthecodinium cohnii

Plant Physiol., 131 (2003), pp. 1681-1691

M.M. Langan, K.D. Hoagland

Growth responses of Typha latifolia and Scirpus acutus to atrazine contamination

Bull. Environ. Contam. Toxicol., 57 (1996), pp. 307-314

C. Leboulanger, F. Rimet, M.H. de Lacotte, A. Bérard

Effects of atrazine and nicosulfuron on freshwater microalgae

Environ. Int., 26 (2001), pp. 131-135

S.D. Lemaire, M. Hours, C. Gerard-Hirne, A. Trouabal, O. Roche, J.P. Jacquot

Analysis of light/dark synchronization of cell-wall-less Chlamydomonas reinhardtii (Chlorophyta) cells by flow cytometry

Eur. J. Phycol., 34 (1999), pp. 279-286

\section{F.M. Lupi, H.M.L. Fernandes, I. Sa-Correia}

Increase of copper toxicity to growth of Chlorella vulgaris with increase of light intensity

Microb. Ecol., 35 (1998), pp. 193-198

\section{A.B. Lyons}

Analysing cell division in vivo and in vitro using flow cytometric measurement of CFSE dye dilution

J. Immunol. Methods, 243 (2000), pp. 147-154 


\section{A.B. Lyons, J. Hasbold, P.D. Hodgkin}

Flow cytometric analysis of cell division history using dilution of carboxyfluorescein diacetate succinimidyl ester, a stably integrated fluorescent probe

Z. Darzynkiewicz, H.A. Crissman, J.P. Robinson (Eds.), Methods in Cell Biology: Cytometry (3rd ed.), vol. 63Academic Press, London, UK (2001), pp. 375-398

K. Matsumura, T. Yagi, K. Yasuda

Role of timer and sizer in regulation of Chlamydomonas cell cycle

Biochem. Biophys. Res. Commun., 306 (2003), pp. 1042-1049

I. Muñoz, M. Real, H. Guasch, E. Navarro, S. Sabater

Effects of atrazine on periphyton under grazing pressure

Aquat. Toxicol., 55 (2001), pp. 239-249

C. Nalewajko, M.M. Olaveson

Ecophysiological considerations in microalgal toxicity tests

P.G. Wells, K. Lee, C. Blaise (Eds.), Microscale Testing in Aquatic Toxicology. Advances, Techniques and Practice, CRC Press, Boca Raton, FL (1998), pp. 289-309

H. Oldenhof, K. Biová, H. Van Den Ende, V. Zachleder

Effect of red and blue light on the timing of cyclin-dependent kinase activity and the timing of cell division in Chlamydomonas reinhardtii

Plant Physiol. Biochem., 42 (2004), pp. 341-348

\section{R.J. Olson, S.L. Frankel, S.W. Chisholm, H.M. Shapiro}

An inexpensive flow cytometer for the analysis of fluorescence signals in phytoplankton: chlorophyll and DNA distributions

J. Exp. Mar. Biol. Ecol., 68 (1983), pp. 129-144

\section{M.G. Ormerod}

Analysis of DNA. General methods

M.G. Ormerod (Ed.), Flow Cytometry. A Practical Approach, Oxford University Press, Oxford, UK (1990), pp. $69-87$ 
J. Parpais, D. Marie, F. Partensky, P. Morin, D. Vaulot

Effect of phosphorus starvation on the cell cycle of the photosynthetic prokaryote Prochlorococcus $s p$ Mar. Ecol. Prog. Ser., 132 (1996), pp. 265-274

C. Rioboo, R. Prado, C. Herrero, A. Cid

Population growth study of the rotifer Brachionus sp. fed with triazine-exposed microalgae

Aquat. Toxicol., 83 (2007), pp. 247-253

H.M. Shapiro

Practical Flow Cytometry

(3rd ed.)Willey-Liss Inc., New York (1995) 542 pp.

M.L. Smith, A.J. Fornace

Mammalian DNA damage inducible genes associated with growth arrest and apoptosis

Mutat. Res., 340 (1996), pp. 109-124

H. Tamiya

Synchronous cultures of algae

Annu. Rev. Plant Physiol., 17 (1966), pp. 1-26

C. Tomlin

The Pesticide Manual. A World Compendium

(13th ed.)BCPC (British Crop Protection Council), UK (2003) 1341 pp.

B.J. Trask, G.J. Van Den Engh, J.H.B.W. Elgershuizen

Analysis of phytoplankton by flow cytometry

Cytometry, 2 (1982), pp. 258-263

A.P. Van Wezel, P. Van Vlaardingen

Environmental risk limits for antifouling substances 
Aquat. Toxicol., 66 (2004), pp. 427-444

M. Vitova, V. Zachleder

Points of commitment to reproductive events as a tool for analysis of the cell cycle in synchronous cultures of algae

Folia Microbiol. (Praha), 50 (2005), pp. 141-149

M. Yamamoto, H. Nozaki, Y. Miyazawa, T. Koide, S. Kawano

Relationship between presence of a mother cell wall and speciation in the unicellular microalga Nannochloris (Chlorophyta)

J. Phycol., 39 (2003), pp. 172-184

Corresponding author. Tel.: +34 981167 000; fax: +34 981167065 .

Copyright @ 2009 Elsevier B.V. All rights reserved. 